\title{
Polypharmacy in a female patient suffering from multiple psychiatric disorders
}

\author{
Authors: Petra Sulić ${ }^{1}$, Marija Škoro ${ }^{2}$, Tomo Trstenjak ${ }^{3}$ \\ ${ }^{1}$ General practitioner's office MD, Marija Petrovčić. Zagreb \\ ${ }^{2}$ Department of Emergency Medicine Vukovar-Srijem County, Vinkovci \\ ${ }^{3}$ University of Zagreb School of Medicine, Zagreb, Croatia \\ DOI: https://doi.org/10.26800/LV-142-supp5-24
}

\section{Introduction:}

Psychiatric polypharmacy refers to the prescription of two or more psychiatric medications concurrently to a patient. Although psychopharmacology advanced and we now better understand the principles of therapeutics, its practice is still increasing. The prevalence of polypharmacy in psychiatry is between $13 \%-90 \%$.

\section{Case report:}

We present a 52-year-old female diagnosed with paranoid schizophrenia, unspecified psychosis not due to a substance or known psychological condition, anxiety disorder, and brief psychotic disorder. She was first diagnosed with paranoid schizophrenia in 2004, after presenting with symptoms of delusions, hallucinations, and disorganized thinking. She was hospitalized and treated with haloperidol. Later she was prescribed clozapine but was not satisfied with it. She started visiting multiple psychiatrists and demand additional pharmacological therapy. In the next fifteen years, she ended up taking Eglonyl, Olandix, Nozinan, Velafax, Moditen, Xanax, Cerson, Calixta, Pregabalin, Zyprexa, Lorsiln, Lexaurin, Prazine, Sanval, Zoloft, and Cymbalta. She combined multiple drugs and dosed herself, as she wanted, despite the doctor's recommendation. She ended up having multiple side effects, like significant tiredness, low energy or problems sleeping, feeling sad or down, inability to cope with daily problems or stress, weight gain, and gastritis. She still takes more than ten medications simultaneously and insists on its positive effects on her health. She has not been able to work for years and has a disability pension.

\section{Conclusion:}

Dealing with polypharmacy requires an understanding of its associated factors. Guidelines, algorithms for the appropriate management of various conditions, and education are effective ways to avoid irrational polypharmacy.

Keywords: polypharmacy, psychopharmacology, psychiatry 